\title{
Multifocal angiomyolipoma involving kidney and regional lymph nodes in patient with tuberous sclerosis complex- A Rare case with review of literature
}

\author{
Prasad Mylarappa', Avinash B Patil', Sandeep Puvvada ${ }^{3}$, Amey Pathade ${ }^{2}$, D Ramesh \\ ${ }^{1}$ Professor and HOD, Department of Urology, M.S. Ramaiah Hospital, Bangalore, India, ${ }^{2}$ Senior Resident, Department of Urology, M.S. \\ Ramaiah Hospital, Bangalore, India, ${ }^{3}$ Assistant Professor, Department of Urology, M.S. Ramaiah Hospital, Bangalore, India, ${ }^{4}$ Senior \\ Professor, Department of Urology, M.S. Ramaiah Hospital, Bangalore, India
}

Tuberous sclerosis complex is rare neurocutaneous syndrome involving central nervous system and lesions in skin. Tuberous sclerosis with multifocal angiomyolipoma involving kidney and lymph nodes is even rarer.

Key words: Tuberous sclerosis complex, Renal angiomyolipoma, Angiomyolipoma in lymph nodes, Nephron sparing surgery, Adenoma sebaceum

\section{Access this article online}

Website:

http://nepjol.info/index.php/AJMS DOI: 10.3126/ajms.v7i2.12618 E-ISSN: 2091-0576

P-ISSN: $2467-9100$

\section{INTRODUCTION}

Renal angiomyolipoma is a benign tumor comprised of three characteristic histologic components: blood vessels, smooth muscle, and mature adipocytes. It is seen in $0.3 \%$ of the population and comprises 3\% of the solid renal masses. ${ }^{1,2}$ Renal angiomyolipoma can occur sporadically or in association with tuberous sclerosis complex (TSC). Sporadic angiomyolipomas are usually single and large tumors and they appear to have a slow growth rate. ${ }^{3}$ TSC-associated angiomyolipomas typically present at a younger age (mean age 30 years); and usually they are multiple, bilateral, and symptomatic tumors. ${ }^{4-6}$ Extrarenal presentations of angiomyolipoma are rare and have been reported in the hilar lymph nodes, retroperitoneum, liver, and with direct extension into the venous system. We present a histopathologically proven rare case of renal angiomyolipoma with regional lymph node involvement in patient with tuberous sclerosis complex.

\section{CASE REPORT}

Twenty-three years old lady presented with complaints of dull aching pain in upper abdomen and left flank pain with hematuria since 2 months. On examination patient was found to have adenoma sebaceum (Figure 1) and rest of general physical examination was normal.

Ultrasonography was suggestive of mass lesion of size $84 \times 40 \times 60 \mathrm{~mm}$ in upper pole of left kidney. Mass lesion was heterogenous in echotexture with multiple hyperechoic areas within (Figure 2). Liver was normal. There were multiple tiny hyperechoic lesions in bilateral renal parenchyma.

CECT was suggestive of $83 \times 38 \mathrm{~mm}$ well defined irregular soft tissue mass in postero-medial aspect of upper pole of left kidney without any calcification. Another two masses of similar character were seen in posterior aspect of lower pole of left kidney measuring $18 \times 20 \mathrm{~mm}$ and $20 \times 21 \mathrm{~mm}$ in size. Another $18 \times 14 \mathrm{~mm}$ fat containing non enhancing mass lesion suggestive of angiomyolipoma was seen in interpolar area of left kidney. Multiple small fat intensity foci were seen in right kidney (Figure 3). Multiple enlarged hilar lymph nodes were noted. There were multiple small cysts in both lungs.

She was suspected to have tuberous sclerosis complex and she was further evaluated. Her fundoscopy was normal. CT 
brain was suggestive of multiple calcified subependymal nodules along the walls of the bilateral lateral ventricles. Few non enhancing calcified cortical and subcortical tubers were also seen in right frontal and left temporal lobes. These features were suggestive of tuberous sclerosis. (Figure 4).

Her 2D echocardiography was normal. Considering patient's age and multifocal angiomyolipoma, she underwent nephron sparing surgery. Left upper pole partial nephrectomy along with enucleation of three small tumors from mid and lower pole of left kidney was performed. Renorrhaphy was done and enlarged hilar group of lymph nodes were dissected and excised (Figure 5).

Microscopically tumors and lymph nodes were comprised of mixed adipose tissue, blood vessels and spindle cells consistent with multifocal angiomyolipomas (Figure 6).

\section{DISCUSSION}

Tuberous sclerosis is an autosomal dominant congenital disease that is characterized clinically by the classical triad of mental retardation, epilepsy, and sebaceous adenoma. ${ }^{7}$ It is rare multisystem genetic disease that causes benign tumors to grow in the brain and other vital organs such as kidney, heart, eyes, lungs and skin. $40 \%$ to $80 \%$ of the patients with tuberous sclerosis present with renal

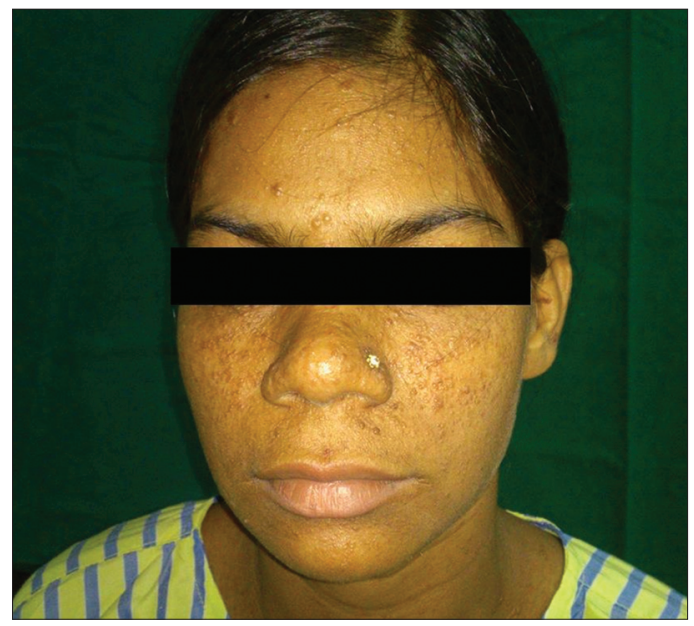

Figure 1: Adenoma sebaceum over nose and cheeks

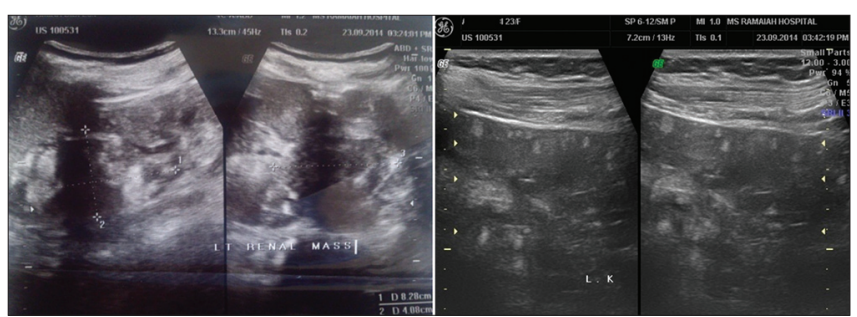

Figure 2: USG showing mass lesion in upper pole of left kidney with multiple hyperechoic lesions in renal parenchyma angiomyolipoma with multiple bilateral asymptomatic tumors, which may be associated with cysts and more rarely renal carcinoma. ${ }^{7,8}$ The angiomyolipoma may affect the perirenal fat and local lymphatic vessels, and the presence of tumors in extra renal sites is considered multicentric and not metastatic. Multifocal angiomyolipomas have been reported in lymph nodes, spleen, liver, inferior vena cava and retroperitoneum. ${ }^{9-12}$

Renal angiomyolipoma can be diagnosed with great accuracy with ultrasonography and CT scan. A typical renal angiomyolipoma is a hyperechoic mass relative to the renal parenchyma. In hyperechoic renal masses, the presence of acoustic shadowing, a hypoechoic rim, and intratumoral cysts are important findings that help distinguish angiomyolipoma from renal cell carcinoma. ${ }^{13}$ Angiomyolipoma can be accurately diagnosed by identifying the intratumoral fat component, which shows negative attenuation on unenhanced CT scans. ${ }^{14}$ Small angiomyolipomas usually less than $4 \mathrm{cms}$ size can be asymptomatic and are detected incidentally in routine ultrasonography or CT scan for some other indications.

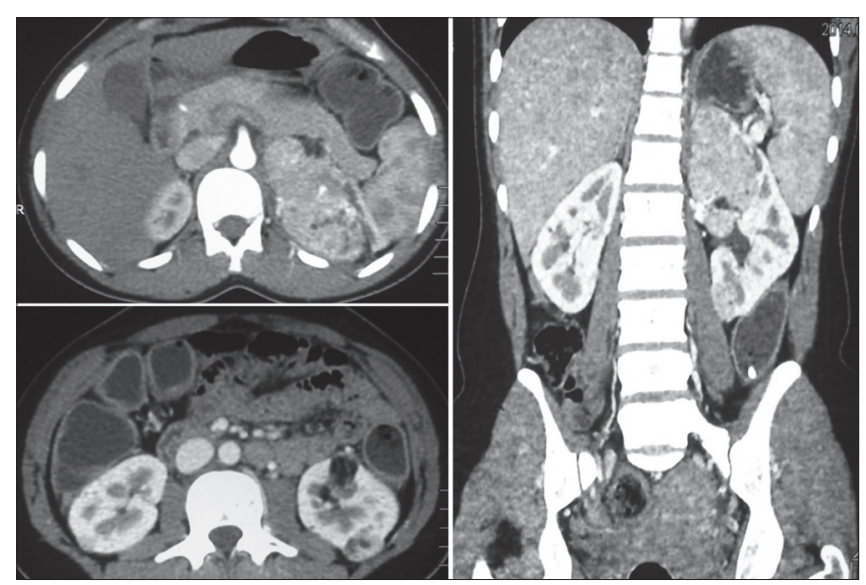

Figure 3: CECT showing $83 \times 38 \mathrm{~mm}$ well defined soft tissue mass in upper pole of left kidney. Multiple soft tissue masses in interpolar region and lower pole of left kidney

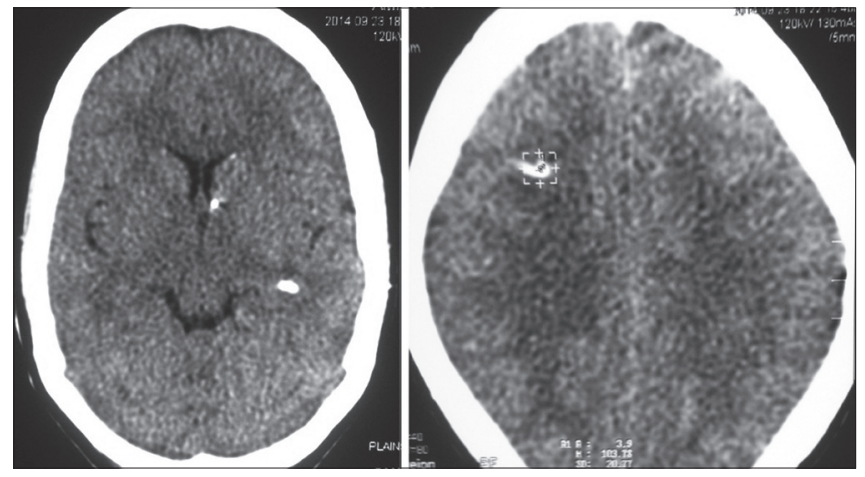

Figure 4: CT brain showing multiple calcified subependymal nodules along the walls of the lateral ventricles. Non enhancing calcified cortical and subcortical tubers were also seen in right frontal lobe 


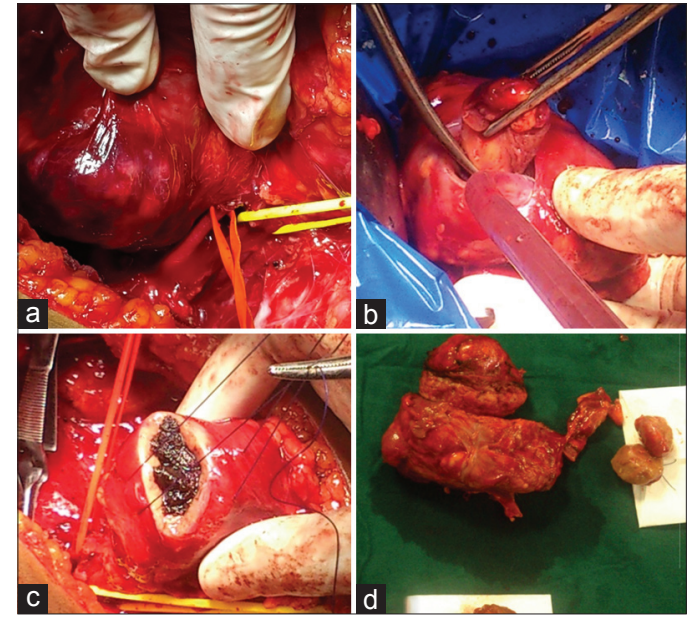

Figure 5: Operative images (a) Tumor in upper pole of left kidney. Renal artery and vein dissected out. (b) Enucleation of lower pole tumor (c) Renorrhaphy performed (d) Large tumor from upper pole and three small tumors from mid and lower pole of left kidney were excised

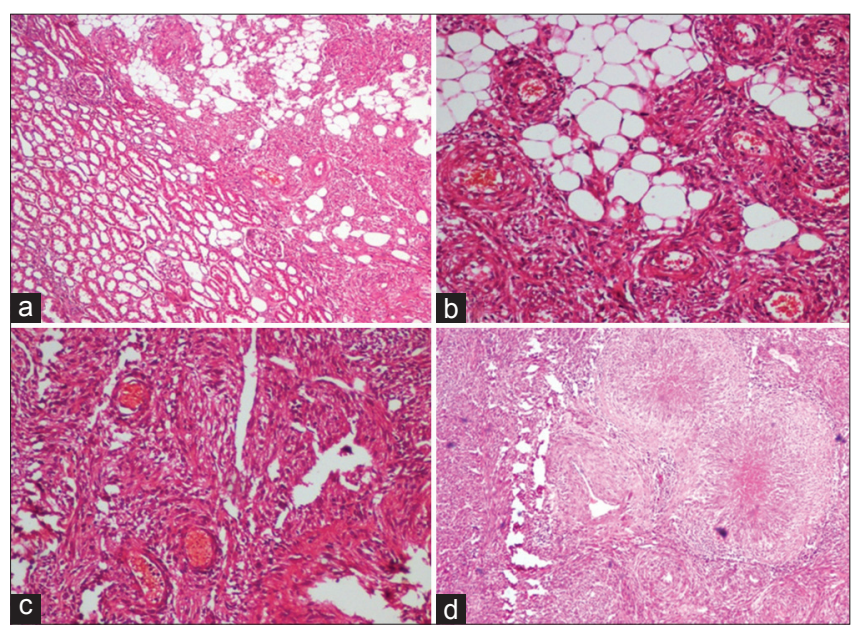

Figure 6: (a) Normal parenchyma with tumour tissue (b) Tumour composed of intimately admixed adipose tissue, blood vessels and spindle cells (c) Congested blood vessels seen which are rimmed by the smooth muscle fibres(d) Epithelioid granulomas with central areas of amorphous necrosis

Tumors more than $4 \mathrm{cms}$ in size can present with flank pain or hematuria. Large tumors pose a significant risk for intratumoral or perinephric hemorrhage. $96 \%$ of individuals with Tuberous sclerosis complex present with dermatological signs like adenoma sebaceum which are characterized by reddish nodules on the nose and cheeks in a butterfly distribution. CT Brain is recommended for patients with renal angiomyolipomas as $30-40 \%$ of these patients may also have features of tuberous sclerosis and similarly $80 \%$ of patients with tuberous sclerosis will develop renal angiomyolipoma. ${ }^{15,16}$ The CT brain of these patients demonstrates characteristic periventricular subependymal nodules with calcifications. ${ }^{17}$ In our patient, CT brain showed multiple calcified subependymal nodules along the walls of the both lateral ventricles and few non enhancing calcified cortical and subcortical tubers in right frontal and left temporal lobes. CECT of KUB region showed $83 \times 38 \mathrm{~mm}$ well defined irregular soft tissue mass in upper pole of left kidney without any calcification. Another three small masses of similar character were seen in mid and lower pole of left kidney which was suggestive of angiomyolipoma of left kidney. Multiple small fat intensity foci were also seen in right kidney. She also had multiple skin lesions on face (adenoma sebaceum). From these findings diagnosis of Tuberous sclerosis complex with bilateral angiomyolipoma was made.

The preservation of renal function is the primary objective of treatment in angiomyolipoma, mainly in those patients associated with tuberous sclerosis, in which the lesions are generally larger, multiple and bilateral. The surgical treatment that is tumor enucleation provides the largest amount of renal tissue preservation. It has excellent results, even for giant angiomyolipoma (larger than $20 \mathrm{~cm}$ ), being practically applicable to patients with tuberous sclerosis who present multiple and bilateral lesions. ${ }^{18-20}$ Our patient underwent partial nephrectomy of upper pole of left kidney with enucleation of mid and lower pole tumors. Enlarged hilar group of lymph nodes were also resected. Histopathological examination of tumors and lymph nodes reveled multi focal Angiomyolipomas with focal epithelioid areas and focal necrotizing granulomatous inflammation. Regional lymph node involvement represents a multicentric nature of the tumor rather than a metastatic disease, as these tumors are benign on pathological examinations and there is lack of evidence of distant spread at more than 10 years follow up in previous reports. ${ }^{21,22}$

\section{CONCLUSION}

In patients with tuberous sclerosis with bilateral and multiple tumors, the aim of treatment is the preservation of the greatest possible degree of efficient renal function. Therefore, tumor enucleation is one of the best choices in these cases.

\section{REFERENCES}

1. Hadju SI and Foote FW Jr. Angiomyolipoma of the kidney: report of 27 cases and review of the literature. J Urol1969; 102:396-401.

2. Mazeman E, Wemeau L, Biserte $J$ and Riquet D. Renal angiomyolipoma. A report of 11 cases. Eur Urol 1980; 6:328-334.

3. Seyam RM, Bissada NK, Kattan SA, Mokhtar AA, Aslam M, Fahmy WE, et al. Changing trends in presentation, diagnosis and management of renal angiomyolipoma: comparison of sporadic and tuberous sclerosis complex-associated forms. Urology 2008; 72:1077-1082.

4. Eble JN. Angiomyolipoma of kidney. Semin Diagn Pathol 1998; 15:21-40. 
5. Lendvay TS and Marshall FF. The tuberous sclerosis complex and its highly variable manifestations. J Urol 2003; 169:1635-1642.

6. Neumann HP, Schwarzkopf G and Henske EP. Renal angiomyolipomas, cysts, and cancer in tuberous sclerosis complex. Semin Pediatr Neurol 1998; 5(4):269-275.

7. Ewalt DH, Sheffield E, Sparagana SP, Delgado MR and Roach ES. Renal lesion growth in children with tuberous sclerosis complex. J Urol 1998; 160:141-145.

8. Van Baal JG, Smits NJ, Keeman JN, Lindhout D and Verhoef S. The evolution of renal angiomyolipoma in patients with Tuberous Sclerosis. J Urol 1994; 152:35-38.

9. Bloom DA, Scardino PT, Egrlich RM and Waisman J. The significance of lymph nodal involvement in renal angiomyolipoma. J Urol 1982; 128:1292-1295.

10. Hulbert JC and Graf R. Involvement of the spleen by renal angiomyolipoma metastasis or multicentricity? J Urol 1983; 130:328-329.

11. Sant GR, Ucci AA Jr and Mears EM Jr. Multicentric angiomyolipoma: renal and lymph node involvement. Urology 1986; 28:111-113.

12. Camunenz $F$, Lafuente $J$, Robledo $R$, Echenagusia $A$, Perez M, Simo G, et al. CT demonstration of extension of renal angiomyolipoma into the inferior vena cava in a patient with tuberous sclerosis. Urol Radiol 1987; 9:152-154.

13. Yamashita $Y$, Ueno $S$, Makita $O$, Ogata I, Hatanaka $Y$, Watanabe $\mathrm{O}$, et al. Hyperechoic renal tumor: anechoic rim and intratumoral cysts in US differentiation of renal cell carcinoma from angiomyolipoma. Radiology 1993; 188:179-182.
14. Sherman JL, Hartman DS, Friedman AC, Madewell JE, Davis CJ and Goldman SM. Angiomyolipoma: computed tomographic-pathologic correlation of 17 cases. AJR Am J Roentgenol 1981; 137:1221-1226.

15. Steiner MS, Goldman SM, Fishman EK and Marshall FF. The natural history of renal angiomyolipoma. J Urol 1993; 150(6):1782-1786.

16. Hajdu SI and Foote FW Jr. Angiomyolipoma of the kidney: report of 27 cases and review of the literature. J Urol 1969; 102(4):396-401.

17. Tsutsumi M, Yamauchi A, Tsukamoto $S$ and Ishikawa S. A case of angiomyolipoma presenting as a huge retroperitoneal mass. Int J Urol 2001; 8(8):470-471.

18. Oesterling JE, Fishman EK, Goldman SM and Marshall FF. The management of Renal Angiomyolipoma. J Urol 1986; 135:1121-1124.

19. Chen $\mathrm{CH}$, Yu TJ and Hsu K. Unusual presentations of angiomyolipoma. Changgeng Yi Xue Za Zhi 1991; 14:269-272.

20. Meiri H, Soejima K, Tokuda $Y$, Miyazaki K,Nakamura K, Kuratomo $\mathrm{K}$, et al. The management selection of renal angiomyolipoma. Nihon HinyokikaGakkai Zasshi 1996; 87:1151-1157.

21. Brecher ME, Gill WB and Straus FH. Angiomyolipoma with regional lymph node involvement and long-term follow-up study. Hum Pathol 1986; 17:962-963.

22. Türker $\mathrm{KI}$, Tunç $\mathrm{M}$, Kiliçaslan I, Ander $\mathrm{H}$, Ozcan $\mathrm{F}$ and Kaplancan T. Lymph nodal involvement by renal angiomyolipoma. Int J Urol 2000; 7:386-389.

\section{Authors Contribution:}

PM- Concept and design of the study, reviewed the literature, manuscript preparation and critical revision of the manuscript; ABP- Concept, collected data and literature search, statistically analyzed and interpreted, prepared first draft of manuscript; SP-Collected data and review of study; AP- Collected data and review of study; DR-Reviewed the literature and critical revision of the manuscript.

Source of Support: Nil, Conflict of Interest: None. 